\title{
A evasão em cursos técnicos a distância
}

\section{Dropout in distance technical courses}

\author{
Renata Luiza da Costa* \\ Júlio César dos Santos**
}

\begin{abstract}
RESUMO
O presente artigo discute os resultados de pesquisa voltada para o estudo da evasão em cursos a distância com foco nos motivos ligados à instituição de ensino. Fundamentados em Heijmans, Fini e Lüscher, Lobo, Vygotsky e Luria, dentre outros referenciais, a pesquisa foi realizada com alunos de cursos técnicos subsequentes a distância de um Instituto Federal. Foram analisados documentos acadêmicos e aplicado questionário semiaberto e online para um grupo de 39 alunos evadidos. Os resultados mostraram que os motivos de evasão ligados à instituição (38\%) são mais concentrados em questões metodológicas do curso a distância e em questões de comunicação interna e externa com a comunidade (divulgação e edital com lacunas). Em torno de $26 \%$ dos alunos citaram frustração com o funcionamento pedagógico do curso: o formato da aula online, o modo de atuação do professor, o apoio às atividades do aluno e a conjugação com momentos presenciais. A partir disso, pudemos inferir que as razões para evasão ligadas à metodologia de ensino e à aprendizagem a distância estão centradas numa sensação de frustração com a aprendizagem devido ao acompanhamento pedagógico insuficiente (carência de contato com o professor e o tutor não ser da área da disciplina), a qual desencadeia sentimentos de não pertencimento institucional e de desprezo pela aprendizagem do aluno, sendo que este último leva a um processo de gradativo desinteresse pelo curso culminando em evasão.
\end{abstract}

Palavras-chave: Evasão. Educação profissional. Educação a Distância. Curso técnico a distância.

DOI: $10.1590 / 0104-4060.50700$

* Instituto Federal de Educação, Ciência e Tecnologia de Goiás. Inhumas, Goiás, Brasil. Campus Inhumas. Av. Universitária s/n. Vale das Goiabeiras. CEP: 75000-000. Email: renata. costa@ifg.edu.br

** Instituto Federal de Educação, Ciência e Tecnologia de Goiás. Goiânia, Góias, Brasil. Campus Goiânia. Rua 75, nº 46, Centro. CEP: 74055-110. Email: julio.santos@ifg.edu.br 


\begin{abstract}
This article aims to discuss the results of a research centered on the study of the dropout phenomenon in distance courses, focusing on the reasons related to the educational institution. Based on Heijmans, Fini and Lüscher, Lobo, Vygotsky e Luria, the research was carried out with students of subsequent technical courses offered by a federal institute. We analyzed academic documents and applied an online questionnaire for a group of 39 former students. The results showed that the reasons for evasion related to the institution (38\%) have more to do with methodological issues of distance learning and internal and external communication with the community (divulgation and gaps in the notice boards). Around $26 \%$ of the students cited frustration with the pedagogical functioning of the course: the online class format, the professor's performance, the support of the student's activities and the conjugation with face-to-face moments. From this, we could infer that the reasons for avoidance as related to the methodology of distance teaching/ learning are centered on a feeling of frustration with the learning process due to insufficient pedagogical accompaniment (lack of online contact with the professor and lack of formation on the tutor's part). These characteristics trigger feelings of not belonging to the institution and contempt for student learning, leading the beginning of a process of disinterest in the course that culminates in the dropout process.
\end{abstract}

Keywords: Dropout. Vocational Course. Distance Education. Distance Technical Course.

\title{
Introdução
}

A oferta de cursos a distância no Brasil tem aumentado em torno de $20 \%$ ao ano (ABED, 2015) e, embora seja, principalmente, nos níveis de graduação e pós-graduação, os cursos técnicos a distância já representam $18 \%$ do total das ofertas de cursos a distância. No caso dos cursos técnicos a distância, nos moldes de educação formal reconhecida pelo Ministério da Educação (MEC), eles foram autorizados no Brasil em 2005 (BRASIL, 2005) junto a outros níveis, mas, apenas em 2008, foram concretizadas as primeiras ofertas. Pioneiras na educação técnica a distância, elas foram implementadas por meio do Programa Rede e-Tec Brasil (BRASIL, 2007), lançado para estimular especificamente a educação profissional técnica a distância com fomento específico.

O Programa Rede e-Tec Brasil, por meio do Fundo Nacional de Desenvolvimento Educacional (FNDE), estimulou a expansão da educação profissional técnica a distância ofertada pelas redes pública e privada. A partir dele, obser- 
vou-se um salto na nas ofertas de ensino a distância de tal nível, em média, 8\% ao ano (ABED, 2015). Esse crescimento, dentre outras razões, tem a ver com os incentivos financeiros por parte do governo e, ao mesmo tempo, pelo aumento da necessidade de formação contínua ao longo da vida do trabalhador que, por diversas razões, não consegue frequentar cursos presenciais regularmente. Nesse sentido, destaca-se o papel social que os cursos a distância têm em ampliar o acesso às formações de qualidade para os trabalhadores.

No entanto, apesar do crescimento na busca por cursos a distância, as taxas de evasão também têm sido altas. Em média, a evasão fica em torno de $40 \%$, mas podem ser encontrados cursos técnicos a distância que apresentam um índice maior que 75\%. Considerando que a evasão está ligada a muitos fatores, a saber: sociais, institucionais e pessoais (HEIJMANS; FINI; LÜSCHER, 2013; DORE; LÜSCHER, 2011; LOBO, 2012), torna-se relevante estudar suas causas com a finalidade de identificar situações que possam ser revistas, na perspectiva institucional, e daí propor estratégias de acompanhamento visando a permanência e êxito dos alunos nesses cursos.

O êxito do aluno no curso traz benefícios tanto para a sociedade, que contará com mais pessoas qualificadas, quanto para a instituição e para o próprio aluno. Do contrário, o insucesso do aluno também gerará problemas de ordem pessoal e social. Com essa preocupação, este texto toma como tema o estudo das causas da evasão escolar em cursos técnicos a distância.

Ademais, em pesquisa realizada na base de dados Scielo, em periódicos com classificação de B3 acima, foram encontrados apenas doze artigos a partir dos descritores "evasão distância" e "evasão técnico". Desses artigos, apenas um era voltado para cursos técnicos (DORE; LÜSCHER, 2011), porém, com estudo de campo em curso presencial. Considerando ainda que Heijmans, Fini e Lüscher (2013) explicam que o nível escolar deve ser considerado nos estudos de evasão, infere-se que o Brasil carece de pesquisas sistemáticas sobre evasão, ainda mais quando se refere a cursos técnicos a distância.

Assim, o objetivo deste artigo é refletir sobre as causas da evasão e suas articulações em cursos técnicos a distância de modo a promover conhecimento que sirva de base para futuras estratégias de permanência e êxito do aluno. Para tanto, além do estudo bibliográfico, foi realizada pesquisa de campo com alunos evadidos de sete cursos técnicos a distância de um Instituto Federal da região Centro-Oeste.

\section{O problema da evasão estudantil}

A evasão estudantil é um problema que não pode ser tratado de maneira descontextualizada porque não se deve a uma causa única ou de uma só natureza, 
e seus corolários também não se restringem à instituição ofertante. Para além da repercussão nas questões orçamentárias e sociais institucionais, a evasão repercute significativamente na vida do estudante e, também, no desenvolvimento do país. As perdas advindas da evasão configuram prejuízos acadêmicos, sociais, culturais, econômicos e, logicamente, subjetivos.

Heijmans, Fini e Lüscher (2013) explicam que o conceito de evasão é amplo devido à sua característica multifacetada. Tais autores apresentam algumas ideias de evasão que podem ser sintetizadas em: a) repetência do aluno na escola; b) saída do aluno da instituição; c) saída do aluno do sistema de ensino.

Para este artigo, adotamos como evasão o caso dos estudantes que iniciaram o curso, mas não o concluíram. Ou seja, trata-se do ponto de vista institucional, da desistência de um curso e consequente evasão da instituição de educação profissional técnica em que se matriculou.

De maneira geral, as pesquisas (LOBO, 2012; CUNHA; TUNES; SILVA, 2001; ABED, 2014, 2015; HEIJMANS; FINI; LÜSCHER, 2013; DORE; LÜSCHER, 2011) mostram que são muitas as variáveis que levam os estudantes a decidirem pela evasão, dentre essas razões de cunho social, pessoal, profissional e institucional. Destaca-se que a maioria dos casos de evasão ocorre já no primeiro ano do curso, sendo ainda mais intensas no primeiro semestre.

Com relação a aspectos externos à instituição, de impacto social, destaca-se a pouca significância do diploma no âmbito social, baixa qualidade da formação na educação básica, a não garantia de suficiência profissional para exercer o trabalho, as limitações dos financiamentos estudantis e até as dificuldades de mobilidade (LOBO, 2012). No que diz respeito a fatores institucionais, as causas que mais aparecem ligadas à instituição são as dificuldades de aprendizagem, atendimento pedagógico insuficiente, o sentimento de não pertencimento à instituição decorrentes de atendimentos precários e desorganização administrativa e comunicacional (BITTENCOURT; MERCADO, 2014; LOBO, 2012; DIAS; THEÓPHILO; LOPES, 2016).

Com relação aos cursos a distância, estudos da ABED mostram que, em $25 \%$ das instituições ofertantes desses cursos, em diversos níveis, a taxa de evasão está em torno de $24 \%$. Porém, em $35 \%$ das instituições, onde os cursos são totalmente realizados a distância, a evasão está entre 26 e 50\% (ABED, 2005, p. 76). Tanto nos cursos totalmente a distância como nos híbridos ${ }^{1}$ aparecem como causas da evasão, primeiramente, a falta de tempo, depois questões financeiras e, em terceiro lugar, a não adaptação à metodologia (ABED, 2014). Apesar da

1 Neste texto, híbrido quer dizer que o curso não é completamente a distância. São articulados momentos presenciais com aqueles a distância, mas não mais que $50 \%$ da carga horária total do curso. 
semelhança nas causas apontadas, as taxas de evasão nos cursos híbridos são menores, em torno de 11 a $25 \%$.

Ressalta-se que, de algum modo, muitos fatores externos se relacionam com os internos, implicando, numa necessária reflexão por parte da instituição do que também é classificado como externo a ela. A exemplo disto observa-se o caso das dificuldades de aprendizagem, da baixa qualidade da formação na educação básica, o status social do diploma e o que a matriz curricular oferece como formação. De todo modo, cabe à instituição trabalhar, também, para minimizar os problemas relacionados às dificuldades de aprendizagem que o aluno traz. Deverá ser preocupação institucional considerar se a formação oferecida atende às demandas sociais relativas ao mundo do trabalho. Nesse sentido, a preocupação com a evasão acaba remetendo às questões de gestão administrativa, acadêmica e pedagógica que sustentam o estudante no curso e que devem ser pensadas desde o seu acesso ao curso.

De acordo com Lobo (2012), a evasão é um problema de gestão ocultado por muitos sob o pretexto de que o maior motivo para que ela ocorra sejam os problemas financeiros que o aluno atravessa.

O maior e mais comum problema que encontramos para combater a Evasão da IES, problema do qual, praticamente, em nossa opinião, derivam todos os demais, está ligado à prática corrente de imputar às questões de ordem financeira do aluno como sendo a grande (e quase única) causa de Evasão da IES. Ou seja, não há a visão de que pode ocorrer Evasão (e ocorre em percentuais alarmantes!) em razão, ou por reflexo de problemas acadêmicos, e, também, administrativos e de atendimento ao aluno. Por isso, a Evasão da IES acaba não sendo tratada como deveria ser: como um problema de gestão institucional. Não é difícil encontrar gestores muito bem-intencionados que chegam a fazer pesquisas junto a alunos desistentes e que simplesmente "aceitam" que o argumento financeiro majoritariamente apresentado é a expressão da pura verdade, pois muitos não sabem, ou se esquecem, de que diversas pesquisas indicam que o aluno, muitas vezes, prefere afirmar que o problema dele é financeiro a ter que enfrentar a reação de sua crítica a setores da IES, ou ao desempenho de docentes, gestores ou funcionários. Por isso, pode ser mais fácil cruzar os braços, ou transferir para a Mantenedora a responsabilidade pelas questões financeiras, e, assim, a Evasão passa a não ser mais um problema dos "acadêmicos", que quase sempre preferem ficar bem distantes desses assuntos. Para mudar a cultura gerencial e acadêmica das IES e aproximá-las um pouco mais da realidade, é fundamental ter em mente que o aluno não é sempre o culpado pela Evasão! (LOBO, 2012, p. 11-12). 
Nessa perspectiva, torna-se relevante compreendermos que a evasão não é um problema de causa única e linear. Nem só de metodologia, nem só de atendimento, nem só financeiro e não, muito menos, só da vida do aluno. Pelo contrário, é resultado de uma complexidade de questões que ao se articularem convencem o aluno de que o melhor a fazer é desistir do curso.

Spady (1970), baseado na teoria do suicídio de Durkheim, explicou que a evasão do aluno é o seu suicídio educacional, que essa decisão é tomada a partir da certeza que o aluno tem de que não é capaz de atender às demandas do processo educacional em que está inserido. Segundo o autor, o aluno rompe com os laços acadêmicos assim como o suicida rompe com os laços sociais a partir da compreensão de que não há mais integração possível com aquele meio social.

Tinto (2005), pesquisador de renome no quesito evasão, expande a teoria de Spady (1970) acrescentando a teoria da troca: o aluno se mantém no processo enquanto acreditar que os benefícios são mais significantes do que os custos de estar ali, entendendo custos de forma ampla. Para o autor, se referindo a cursos de graduação, é preciso formar pedagogicamente os professores, dar mais atenção ao primeiro ano do curso, oferecer condições de nivelamento para os alunos com maiores dificuldades e ainda cuidar dos alunos mais avançados para que não se desinteressem pelo curso.

Pesquisas da Escola de Vygotsky (VYGOTSKY, 1931; VYGOTSKY; LURIA, 2007; DAVYDOV, 1988, 1999) também explicam que é por meio das mediações socioculturais que são possíveis processos de ensino-aprendizagem significativos que façam sentido para o aluno, o que afeta seu engajamento. Segundo Vygotsky e Luria (2007, p. 84), os processos de ensino-aprendizagem devem considerar a relação cognitivo-afetiva do processo, pois com a ausência de tal dimensão "[...] se produz inevitavelmente a subestimação da ação voluntária, da ação em suas formas superiores...".

Davydov (1988, p. 147) explica que o desejo é o elemento essencial de todo engajamento, responsável pela decisão do indivíduo em se empenhar na atividade e que deve ser gerado nas próprias atividades de estudo, de modo que o aluno obtenha um "novo produto espiritual, ou seja, de conhecimento desse material" (DAVYDOV, 1999, p. 2). Assim, as atividades em que o aluno aprende gera nele um sentimento de satisfação porque tem sua expectativa atendida, ou seja, confere-lhe significado. A partir disso, ele tem renovado seu interesse por novas aprendizagens e permanece engajado. Nesse sentido, nota-se que o modo como as relações sociais pedagógicas ocorrem é fundamental para consolidar certo nível de participação dos alunos e, consequentemente, sua aprendizagem e permanência no curso. 


\section{A evasão estudantil em cursos técnicos}

As primeiras ofertas de cursos técnicos a distância, regulamentadas pelo Ministério da Educação, ocorreram por meio do Programa Rede e-Tec (BRASIL, 2011). Embora esse Programa caracterize-se por algo novo na educação formal brasileira e venha acontecendo desde 2007, ele não foi, até então, avaliado qualitativamente (COSTA, 2015). Os dados publicados até 2015 dizem respeito apenas à quantidade de polos espalhados pelo país e, ainda assim, numa perspectiva muito difusa que não nos permite sequer verificar se houve interiorização da oferta de educação profissional técnica gratuita.

Em alguns estudos localizados, voltados para os cursos da Educação Profissional Técnica presencial (DORE; LÜSCHER, 2011; ALKMIM; SOUZA, 2014; ARAÚJO; PARENTE JÚNIOR, 2014), pode-se observar que o perfil do aluno é de baixa renda, moradores de áreas periféricas das grandes cidades, cidadãos que utilizam regularmente o transporte público, cidadãos que têm necessidade de trabalhar para complementar renda na família, em sua maioria mulheres com dificuldades familiares com filhos, dentre outras questões pessoais e profissionais. Esse perfil, grosso modo, aponta para questões sociais como sendo de forte influência para a decisão pela evasão.

De acordo com Dore e Lüscher (2011), a partir de pesquisa realizada pela Secretaria do Estado de Minas Gerais, a evasão em cursos técnicos foi justificada por $36,9 \%$ dos indagados pela necessidade de trabalhar ou se manter no trabalho, seguido de $20 \%$ que afirmaram não ter razão específica. Na época da pesquisa realizada pela supracitada secretaria, em 2008, a evasão desses cursos era de $27,9 \%$, sendo considerada altíssima, uma vez que os cursos técnicos pesquisados eram gratuitos, e, ainda, os alunos recebiam bolsa como apoio financeiro. A respeito disso, as autoras (DORE; LÜSCHER, 2011, p. 785-786) asseveram:

Nesse sentido, a pesquisa sobre causas para a evasão escolar deve incluir, necessariamente, além das motivações individuais, os fatores associados à esfera de competência e de atuação da instituição escolar; por exemplo, as áreas tecnológicas em que os cursos são ofertados, as práticas pedagógicas, a programação das disciplinas, os programas de estágio e de outras práticas profissionais, os processos de avaliação, a formação docente, dentre outros aspectos. [...] O resultado do monitoramento da evasão no PEP é inequívoco quanto à necessidade de aprofundar o conhecimento das causas da evasão estudantil e de desenvolver medidas capazes de evitar o problema. A existência de evasão tão elevada em cursos técnicos 
organizados a partir de uma política pública, que busca expressamente privilegiar a formação profissional como recurso de inserção dos jovens no mercado de trabalho, remete nossas reflexões, mais uma vez, para o contexto da política educacional brasileira na organização da escola média e da escola técnica. É indispensável que a atual política educacional para o ensino técnico, ao desenvolver suas estratégias de expansão, considere a evasão escolar e suas principais causas, de forma a evitar o risco de decisões equivocadas e onerosas. Para além dos fatores individuais, a identificação e a análise dos fatores intraescolares que intervêm nos processos de evasão são dimensões que não podem ser desconsideradas na implantação e avaliação da política pública para o ensino técnico, seja no plano federal, estadual ou municipal. A definição de áreas ou de eixos tecnológicos para a oferta de cursos técnicos é, sem dúvida, decisiva para permanência ou não de estudantes nas escolas técnicas.

Outras pesquisas (HEIJMANS; FINI; LÜSCHER, 2013; DORE; LÜSCHER, 2011) explicam que a evasão é um fenômeno de múltiplas razões e não pontual, ou seja, ocorre em processos que apresentam indícios anteriores que podem vir a ser tratados, sendo a evasão seu ápice.

No que diz respeito a fatores indutores da evasão de características sociais, podemos destacar as relações familiares, as condições de trabalho e emprego, e as expectativas socioprofissionais para com o curso. Já os fatores institucionais abrangem desde a área do curso oferecido, seu significado social, expectativas do aluno com as aprendizagens, chegando, por fim, à metodologia de ensino e aprendizagem:

A permanência/persistência do estudante ou o seu abandono da escola são possibilidades estreitamente relacionadas ao reconhecimento, pela instituição escolar, da existência de fatores, presentes no percurso do estudante, favoráveis ou não ao seu desempenho. [...] O insucesso escolar produz consequências imediatas e diretas sobre o modo pelo qual o jovem se percebe como estudante, que são prejudiciais e podem ainda ter efeitos persistentes e continuados no tempo. Um baixo conceito de si mesmo, como estudante, pode induzir a uma percepção generalizada de escassa autoeficácia e a uma negativa autoatribuição, isto é, à sensação de não ser capaz de modificar, com os próprios esforços, o andamento dos eventos escolares... O passo seguinte é constituído pelo enfraquecimento dos laços com a escola... (HEIJMANS; FINI; LÜSCHER, 2013, p. 248, 258-259). 
Costa (2015), a partir de sua pesquisa específica com cursos técnicos subsequentes a distância, mostrou que os estudantes manifestam sentimento de abandono e isolamento com relação aos professores e tutores decorrente da metodologia adotada. Os alunos destacam que, no ambiente online, prevalece a demora no atendimento as suas demandas, e o professor se faz ausente, relegando ao tutor suas atividades. Consideram, ainda, que o tutor não tem formação na área e oferece um atendimento precário, dentre outras situações relatadas que fortalecem sentimentos negativos com relação à instituição e/ou em relação a si mesmo.

\section{A evasão em cursos técnicos a distância}

No Instituto Federal pesquisado, os cursos técnicos a distância começaram a ser ofertados a partir de 2010. De início, foi implantado apenas um curso técnico subsequente a distância. Atualmente, esta escola oferta três cursos diferentes, apresentando um alto índice de evasão, em média, $40 \%$ conforme relatórios internos da respectiva instituição.

Os cursos pesquisados são todos técnicos de nível subsequente ao Ensino Médio e não são completamente a distância. Atendendo às diretrizes nacionais para a educação profissional técnica, todos eles possuem $20 \%$ de carga horária presencial.

Por meio de formulário online, enviado por e-mail para 401 contatos de alunos evadidos das turmas de 2014 e 2015, foram obtidas 39 respostas comentadas. Assim, trabalhamos com uma amostra de 11\% do universo de alunos evadidos no período mencionado. Também foram analisados documentos administrativos e acadêmicos, tais como os projetos pedagógicos dos cursos, as atividades realizadas no ambiente online e nos encontros presenciais e editais de seleção dos alunos. No formulário, os participantes podiam marcar mais de uma resposta a respeito dos motivos de evasão e de sua avaliação do curso, além de poder comentar no final.

A análise dos dados mostrou que, dos alunos evadidos, $45 \%$ abandonaram o curso por motivos diversos não mencionados. Outros $23 \%$ afirmaram ter sido devido a problemas pessoais, $20 \%$ afirmaram ter sido porque o curso era difícil e $12 \%$ por ter tido problemas no trabalho. Além disso, $4 \%$ dos estudantes mencionaram ter dificuldades técnicas com uso do computador, da internet ou do ambiente virtual de ensino e aprendizagem, e 7,7\% dos alunos afirmaram não ter gostado da experiência de estudar a distância. Alguns destes últimos explicaram 
que não conseguem estudar sempre sozinhos em casa e as poucas aulas presenciais não eram com o professor, mas sim uma videoaula com acompanhamento de um tutor sem formação na área da disciplina. Essas duas últimas observações merecem destaque: $30 \%$ dos alunos disseram que os tutores não conseguiam responder suas dúvidas sobre o conteúdo e que não havia aulas práticas em laboratórios, nem visitas técnicas necessárias à sua prática profissional técnica.

Também foi bem mencionada (11\%) a frustração com o conteúdo do curso e seu funcionamento. Alguns alunos detalharam que o edital de seleção e ingresso não explicava que as aulas presenciais seriam semanais e aos sábados matutinos. As aulas presenciais, na verdade, eram transmissões de videoaulas com a presença de um tutor inespecífico. Este, por não dominar o conteúdo da disciplina, tinha seu papel reduzido a um apoio técnico-administrativo e não pedagógico. Pode-se observar que a frustração com o funcionamento dos cursos a distância foi fator decisivo para um grande número de alunos evadir. Os alunos mencionaram que pensavam que o curso a distância teria professores online. $\mathrm{Ou}$ seja, a realidade do funcionamento pedagógico do curso levou-os a se frustrarem com a expectativa de aprendizagem. Os dados mostraram, ainda, que a comunicação interna é precária, desencontrada, departamentos e alunos apresentam desconhecimento sobre o departamento de EaD nos respectivos polos.

Analisando a organização desses cursos a partir dos projetos pedagógicos, foi possível observar que, de fato, o modelo configurado pela instituição produziu um curso com pouca interação entre professores e estudantes e quase nenhuma aula prática. Retomando Vygotsky e Luria (2007), o não contato com o professor nesses cursos afetou o desejo deles de continuar. Quando o professor demora a responder ou não responde e o aluno recorre a um tutor que também não é capaz, o aluno desanima por se sentir desamparado pedagogicamente, uma vez que não tem com quem tirar as suas dúvidas sobre as atividades. Assim, a relação de afetividade que se fala não se restringe às interações com foco amistoso entre as partes envolvidas, mas se constitui de uma relação amistosa em função do objetivo de aprendizagem que o aluno busca desde que se inscreve no curso.

Nessa perspectiva de estudo individualizado, os alunos caem numa situação de isolamento que os deixa mais vulneráveis à possibilidade de desistência. Isso vai de encontro aos objetivos sociais dos programas de educação a distância que têm utilizado o argumento da necessária qualificação profissional dos cidadãos habitantes de regiões periféricas do país, porque demonstra que se preocupam apenas em ofertar vagas, e não com a qualidade da formação ou com a permanência dos alunos nos cursos. De acordo com Heijmans, Fini e Lüscher (2013, p. 237), a democratização da educação não pode ser reduzida às questões de acesso: 
De maneira geral, o abandono/evasão na educação básica, ou mesmo na formação técnica de nível médio, vincula-se ao maior ou menor grau de democratização do acesso da população a esses níveis de ensino. Aqui se entende por democratização do acesso tanto as oportunidades de ingresso como as condições oferecidas pela escola e pelo sistema de ensino para permanência/persistência do estudante até a conclusão do nível escolar em que se encontra.

Dar oportunidades educacionais sem, contudo, oferecer o devido acompanhamento e seriedade com a formação dos alunos é insuficiente para alcançar os objetivos socioeducativos desejados. Conforme Spady (1970) e Tinto (2005) explicam, é preciso que o aluno seja acompanhado, que tenha apoio para superar suas dificuldades e vá entendendo que é capaz de aprender conforme se dedica, tendo sempre retorno deste acompanhamento. Ao mesmo tempo, isso reforça os laços acadêmicos e os benefícios do curso passam a valer a pena em relação aos custos.

Com relação aos problemas de edital, foi surpresa a quantidade de pessoas que mencionou ter desistido do curso por não saber que o curso teria aulas semanais presenciais. Percebeu-se, então, que muitos casos de evasão poderiam ter sido evitados se o aluno pudesse ter se organizado solicitando a devida liberação junto ao seu trabalho. $\mathrm{O}$ fato é que a desinformação para um público trabalhador sempre vai tender para desistência, afinal sua atividade prioritária é o trabalho. Analisamos os dois últimos editais de seleção (2014 e 2015) de alunos da instituição pesquisada e, de fato, não há menção à parcela presencial requerida pelo curso, nem sua frequência e dia da semana em que ocorreria. Se em qualquer processo educacional os processos comunicacionais são importantes, nos cursos a distância são ainda mais.

Ainda com relação à comunicação externa, a divulgação sobre as ações do curso na cidade do polo e nos interiores foi citada como falha. No que diz respeito à comunicação interna, trata-se de um problema de gestão pedagógica e administrativa. Observou-se pouco envolvimento institucional. Segundo Lobo (2012), é preciso que a gestão compreenda que o acompanhamento das evasões deve ser um trabalho especializado, contínuo e permanente, devendo mudar a cultura gerencial e acadêmica das instituições de ensino de modo a aproximá-las mais da realidade, entendendo-a como um problema de gestão. Assim, seja no âmbito pedagógico, comunicacional ou acadêmico, ao mesmo tempo que a gestão precisa orientar para o sistemático acompanhamento, também é preciso dar suporte para as mudanças identificadas como necessárias.

Algumas questões pedagógicas são passíveis de serem solucionadas horizontalmente, muitas outras não. Por exemplo, oferecer formações pedagógicas 
adequadas para todo corpo docente, formações sobre processos educativos a distância a todos os técnicos participantes, funcionamento pleno da instituição aos sábados etc. Nesse sentido, o envolvimento institucional é essencial para o bom funcionamento do curso em todas as suas etapas, desde antes do seu início. Lobo (2012, p. 12) destaca que "o fenômeno da Evasão é um problema de gestão, que envolve vários elementos e vários níveis hierárquicos da instituição de ensino superior, não apenas a alçada do Coordenador de Curso, ou do setor financeiro, como muitas vezes lhes é imputado".

\section{Palavras finais}

Diante dos fatos detectados por essa pesquisa, foi possível observar que também nos cursos técnicos a distância, os motivos de evasão se dividem entre os muitos aspectos externos e internos à instituição. Considerando que o objetivo desse estudo foi desvelar elementos que possam ser tratados institucionalmente de modo a aumentar as taxas de permanência e êxito dos alunos, chama-se a atenção, principalmente, para as formas de divulgação dos cursos, a clareza dos editais e a metodologia pedagógica adotada.

Com relação à divulgação dos cursos, ficou claro que os alunos têm recebido informações insuficientes ou truncadas com relação às atividades pedagógicas e ao funcionamento institucional. Os próprios alunos parecem desconhecer os regulamentos e, consequentemente, os benefícios que a instituição pode lhes oferecer. Alguns chegam ao final do curso sem saber das condições necessárias, principalmente, das horas complementares e do estágio, para a conclusão do curso. Também há servidores nessa condição de desconhecimento. Isso tem cooperado com a proliferação de informações inadequadas fornecidas aos estudantes, levando-os, muitas vezes, a não terem seus problemas resolvidos ou resolvidos apenas de maneira parcial. Todas essas situações podem, certamente, desmotivar os alunos dos cursos a distância, pois têm a contínua sensação de que não são reconhecidos na e pela instituição porque não lhes é dada a devida atenção aos seus processos formativos.

No contexto externo, as falhas de divulgação prejudicam a formação de novas turmas. Existem, ainda, muitas pessoas que sequer conhecem os institutos federais, não sabendo que são instituições de educação pública e gratuita. Além disso, observa-se que ao longo do ano não são feitos projetos para que a comunidade possa conhecer a escola. Normalmente, a divulgação é concentrada apenas no período de inscrição para os cursos, num período reduzido e em mí- 
dias que não alcançam determinadas classes. Nos casos dos cursos a distância, a divulgação dos editais, que se dá somente por sítios da internet, não chega a uma parcela específica da população interiorana que não possui computador e internet em casa. Desse modo, é preciso rever as formas de comunicação utilizadas para alcançar a comunidade de maneira clara que de fato informe as pessoas.

Com relação à clareza dos editais de seleção de alunos, eles se mostram falhos porque apenas citam que o curso é a distância. Nesse caso, subentende-se que o curso é todo a distância quando, entretanto, existem aulas semanais ou mensais, dependendo do curso, e que são presenciais no polo. Esse fator de desconhecimento do funcionamento do curso, associado ao público trabalhador que busca por cursos a distância e precisa negociar seus horários com a empresa, acaba direcionando o aluno para a evasão.

No que diz respeito à metodologia pedagógica dos cursos a distância pesquisados, os fatores mais citados como desencadeadores da evasão foram: demora nos atendimentos ou simplesmente não atendimento, atendimento com profissional sem domínio de conteúdo e aulas presenciais insuficientes. Nesses quesitos destacam-se, ainda, a comunicação entre estudantes, tutores e professores que não ocorre satisfatoriamente e, também, professores que não desenvolvem atividades online com os alunos e aulas presenciais com videoaulas reproduzidas, sem o devido acompanhamento de um professor da área e sem possibilidades de práticas profissionais em campo ou laboratórios. A articulação desses fatores indica que o trabalho pedagógico dos cursos técnicos a distância deve ser repensado tanto no ambiente virtual quanto no que se espera de sua complementação nos momentos presenciais. A indiferença e os atendimentos, que não solucionam as necessidades de aprendizagem dos alunos, os levam a um sentimento de baixa autoestima por não conseguirem ter um desempenho satisfatório e, isso, certamente, gera desmotivação. Com isso, se inicia o processo de evasão: ao não corresponder com as expectativas de aprendizagem se desencadeia um processo de frustração que desmotiva e, na sua persistência, o aluno decide desistir. Nos níveis de educação profissional e superior que são subsequentes ao Ensino Médio é preciso considerar que não há obrigatoriedade de estudos por parte do sistema educacional e, por se tratarem de adultos, quase sempre terão dificuldades em conciliar estudos e vida familiar, mesmo que isso venha beneficiar a eles no futuro. Ou seja, o adulto que busca por um curso o faz por desejo próprio, podendo ou não ser estimulado pela família, e/ou por necessidades profissionais. Assim, se o curso não corresponde no sentido de proporcionar aprendizagem significativa para o indivíduo para as conquistas que planeja, ele mantém pouca motivação para sustentar sua permanência no curso.

Conclui-se, portanto, que muitos casos de evasão são concretizados em consequência do ingresso no curso com informações insuficientes, editais am- 
bíguos e até desconhecimento do que seja a profissão. Por outro lado, o oposto desses fatores contribuiria muito para entrarem no curso estudantes conscientes da dedicação necessária ao curso, conscientes do seu funcionamento e até dos objetivos formativos para alcance da qualificação profissional. Nesse caso, ainda que haja outros percalços como, por exemplo, frustração com professores, frustração com condições de estudos e, até mesmo, problemas individuais como os financeiros, eles nem sempre serão tão decisivos para o aluno abandonar o curso devido ao seu real interesse inicial.

Diante do exposto, compreendemos que a avaliação contínua dos cursos técnicos a distância, com viés pedagógico e social junto à comunidade, é um rico universo para traçar estratégias de permanência que ainda é pouco explorado e necessita de pesquisas sistemáticas. Avaliações considerando alunos concluintes, evadidos, a comunidade em geral, a comunidade de empregadores na região são outros exemplos de pesquisas ainda carentes no campo da educação profissional e que podem ajudar a propor ajustes nos cursos.

\section{REFERÊNCIAS}

ABED. Censo EaD.br: Relatório Analítico da Aprendizagem a Distância no Brasil 2013. Curitiba: Ibpex. 2014. Disponível em: <http://www.abed.org.br/censoead2013/ CENSO_EAD_2013_PORTUGUES.pdf $>$. Acesso em: 3 abr. 2015.

ABED. Censo EaD.br: Relatório Analítico da Aprendizagem a Distância no Brasil 2014. Curitiba: Ibpex. 2015. Disponível em: <http://www.abed.org.br/censoead/censoEAD. BR_2012_pt.pdf>. Acesso em: 3 abr. 2016.

ALKMIM, G. V.; SOUZA, H. G. Entre a escola e o trabalho: trajetória dos evadidos dos cursos técnicos do Instituto Federal do Norte de Minas Gerais. In: WORKSHOP NACIONAL SOBRE EVASÃO NA EDUCAÇÃO PROFISSIONAL TÉCNICA E TECNOLÓGICA, 2, 2014, Brasília. Anais... Disponível em: <http://ocs.ifb.edu.br/index.php/ iiwee/workshopevasao/schedConf/presentations>. Acesso em: 12 jan. 2017.

ARAÚJO, F.; PARENTE JÚNIOR, G. Um estudo de caso sobre a evasão nos cursos técnicos subsequentes de nível médio do IFCE - campus Acaraú no período de 2010 a 2013. In: WORKSHOP NACIONAL SOBRE EVASÃO NA EDUCAÇÃO PROFISSIONAL TÉCNICA E TECNOLÓGICA, 2, 2014, Brasília. Anais... Disponível em: <http:// ocs.ifb.edu.br/index.php/iiwee/workshopevasao/schedConf/presentations $>$. Acesso em: 12 jan. 2017. 
BITTENCOURT, I. M.; MERCADO, L. P. L. Evasão nos cursos na modalidade de educação a distância: estudo de caso do Curso Piloto de Administração da UFAL/UAB. Ensaio: Aval. Pol. Públ. Educ., Rio de Janeiro, v. 22, n. 83, p. 465-504, abr.jun. 2014.

BRASIL. Lei $n^{\circ} 11.195$, de 18 de novembro de 2005. Altera o $\S 5^{\circ}$ do art. $3^{\circ}$ da Lei $n^{\circ} 8.948$, de 8 de dezembro de 1994, que estabelece as diretrizes e bases da educação nacional.

BRASIL. Decreto n ${ }^{\circ}$ 6.301, de 12 de dezembro de 2007. Institui a Escola Técnica Aberta do Brasil: e-Tec. Disponível em: <http://www.planalto.gov.br/ccivil_03/_Ato20072010/2007/Decreto/D6301.htm>. Acesso em: 3 set. 2016.

BRASIL. Decreto $n^{\circ} 7.589$, de 26 de outubro de 2011. Institui a Rede e-Tec Brasil. Disponível em: <http://www.planalto.gov.br/ccivil_03/_Ato2011-2014/2011/Decreto/ D7589.htm\#art9>. Acesso em: 19 nov. 2016.

COSTA, R. L. Educação profissional técnica de nível médio a distância: estudo da mediação docente no modelo da Rede e-Tec Brasil na rede federal. 2015. Tese (Doutorado em Educação) - Programa de Pós-Graduação Stricto Sensu em Educação, Pontifícia Universidade Católica de Goiás, Goiânia. 2015.

CUNHA, A. M.; TUNES, E.; SILVA, R. R. da. Evasão do Curso de Química da Universidade de Brasília. Química Nova, São Paulo, v. 24, n. 2, mar./abr. 2001.

DAVYDOV, V. V. Problemas do ensino desenvolvimental: a experiência da pesquisa teórica e experimental na psicologia. Tradução de José Carlos Libâneo e de Raquel A. M. da M. Freitas. Textos publicados na Revista Soviet Education, Vol. XXX, nº 8, 1988, sob o título "Problems of Developmental Teaching. The Experience of Theoretical and Experimental Psychological Research - Excerpts", a partir do original russo. DAVYDOV, V. V. La enseñanza escolar y el desarrollo psíquico. Moscú: Editorial Progreso, 1988. Nota: tradução do russo para o inglês da obra mencionada, para uso didático, na disciplina Didática na perspectiva histórico-cultural, no PPGE da Universidade Católica de Goiás.

DAVYDOV, V. V. O que é a atividade de estudo? Revista Escola inicial, n. 7, 1999.

DIAS, E. C. M.; THEÓPHILO, C. R.; LOPES, M. A. S. Evasão no ensino superior: estudo dos fatores causadores da evasão no curso de ciências contábeis da universidade estadual de montes claros - UNIMONTES - MG. In: CONGRESSO USP DE INICIAÇÃO CIENTÍFICA EM CONTABILIDADE, 13, 2016, São Paulo. Anais do XVI USP International Conference in Accounting. Disponível em: <http://www.congressousp. fipecafi.org/anais/artigos102010/419.pdf>. Acesso em: 13 jan. 2017.

DORE, R.; LÜSCHER, A. Z. Permanência e evasão na educação técnica de nível médio em Minas Gerais. Cadernos de Pesquisa, v. 41, n. 144, set./dez. 2011. Disponível em: $<$ http://www.scielo.br/pdf/cp/v41n144/v41n144a07.pdf>. Acesso em: dez. 2016.

HEIJMANS, R. D.; FINI, R.; LÜSCHER, A. Z. Insucesso, fracasso, abandono, evasão... um debate multifacetado. In: CUNHA, D. M. et al. (Orgs.). Formação/Profissionalização de Professores e Formação Profissional e Tecnológica: Fundamentos e reflexões contemporâneas. Belo Horizonte: Editora PUC-Minas, 2013. 
LOBO, R. Panorama da evasão no ensino superior brasileiro: aspectos gerais das causas e soluções. ABMES, Cadernos n. 25, 2012. Disponível em: $<$ http://www.institutolobo. org.br/imagens/pdf/artigos/art_087.pdf>. Acesso em: 21 nov. 2016.

SPADY, W.G. Dropouts from higher education: An interdisciplinary review and synthesis. Interchange, v. 1, n. 1, 1970.

TINTO, V. Student Success and the Construction of Inclusive Educational Communities. American Association of State Colleges and Universities - AASCU, 2005.

VYGOTSKY, L. S. Historia del Desarrollo de las Funciones Psíquicas Superiores. Obras Escogidas Tomo III. Comisión editorial para la edición en lengua rusa. Academia de Ciencias Pedagógicas de la URSS, 1931.

VYGOTSKY, L. S.; LURIA, A. R. El instrumento y el signo en el desarrollo del niño. Edición a cargo de Pablo del Río y Amelia Álvarez. Fundación Infancia y Aprendizaje, 2007.

Texto recebido em 16 de fevereiro de 2017. Texto aprovado em 15 de março de 2017. 